\title{
Challenging public health acceptability of current international standards on tobacco products: paving the way for strengthened cooperation
}

As tobacco control efforts gain worldwide momentum, policy makers, scientists, and public health advocates are focusing on the development of an appropriate set of international standards to regulate tobacco products. Often forming the technical basis of national regulations, international standards for tobacco have a widespread impact on growers, manufacturers, and consumers.

Established in 1947, the International Organization for Standardization (ISO) is a global federation of national standards bodies from 130 countries with a mission "to facilitate trade, exchange and technology transfer through . . .improved health, safety and environmental protection, and reduction of waste ..."12 Over the past two decades, ISO has developed 36 standards under technical committee 126 related to tobacco and tobacco products. The published standards range in scope from "Sampling of batches of raw material" to "Routine analytical cigarette-smoking machine-definitions and standard conditions." 34

In recent years, one of ISO's most widely used tobacco standards has come under fire. It is now recognised that ISO's routine analytical smoking machine used to measure, regulate, and label tobacco products does not accurately determine a smoker's intake. In fact, Bates and colleagues argue that current ISO tests act to legitimise "the false claims of low tar cigarettes." Development of novel tobacco products, such as RJ Reynolds' Eclipse cigarette, also point to the urgent need to evaluate the true effect of emerging technologies. As a critical step in the development of the Framework Convention on Tobacco Control (FCTC) of the World Health Organization (WHO), a key conference on "Advancing knowledge on regulating tobacco products" concludes that ISO and the US Federal Trade Commission (FTC) tests are not intended to assess the biological or epidemiological impact of tobacco products. It challenges ISO to "ensure that its members recognize and adhere to the principle that ISO/ FTC measurements and methods are used to monitor performance and not health impacts of tobacco product." ${ }^{\prime 6}$

Clearly, ISO is not fulfilling its pledge to improve health in the area of tobacco and tobacco products, as stated in its mission "to facilitate trade . . .through . . .improved health."2 This commentary explains why ISO has been unable to create international standards on tobacco which address public health concerns, and explores alternative structures for tobacco standards development.

\section{What went wrong?}

ISO's standards development process-The tobacco industry has dominated the process of international tobacco standardisation, not only because of the industry's might and tactics but also because of the way in which ISO develops standards. ISO standards are developed on the principles of market relevance, voluntary participation by major stakeholders, and industry wide usage. Standards are initiated when an industry sector expresses the need for a standard to a national standards body. When the need is formally agreed upon by ISO members, the work item is incorporated into the programme of work of an appropriate technical committee or subcommittee.

Drafting, negotiations, and voting - At the preparatory stage, representatives from industry, government, non-governmental organisations, consumer groups, and research institutions from member countries and external liaison organisations are, in principle, invited to participate in the technical work. Once a draft standard has been developed by the members of the technical committee and its working groups, national standards bodies and external parties then participate in the negotiations. It is the responsibility of each national standards body to ensure that its delegation represents a concerted national view at the technical committee discussions. In the end, the final draft international standard is passed with a $75 \%$ majority of all ISO members who vote. ${ }^{7}$

Multinational companies dominate the process - In the case of tobacco, ISO's process of standards development has become vulnerable to the influence of the tobacco industry. In a recent issue of ISO's Bulletin, Linda Lusby, chair of the Standards Council of Canada, admits that "multinational companies play a large role in ISO and IEC, while small businesses, governments, non-governmental organizations and consumers are often excluded due to the cost of participation." ISO standards are privately funded to ensure that governments do not control the standardisation process. Hence, only those participants, including technical experts, with the means of volunteering their time and travel expenses may contribute to the development process.

Tobacco companies host technical committee meetings-Multinational companies also procure more control and influence by hosting technical committee and subcommittee 
meetings. ISO and various technical committees are often indebted to the companies that volunteer resources for the development of standards. On official documents, for example, the British Standards Institute was the host for the October 1999 ISO technical committee 126 meeting on tobacco. But according to meeting information for delegates serviced on the Internet, the ISO meeting organisers were "very obliged" to Imperial Tobacco, Gallagher, BAT, Rothmans, and Filtrona Instruments and Automation companies for their invitation. ${ }^{9}$

Other channels of influence by tobacco companies-Money and other resources are not the only advantages that tobacco companies enjoy. They exert their influence through multiple channels. As Bialous and Yach ${ }^{10}$ explain in this issue of Tobacco Control, the technical work of producing tests and other scientific evidence is almost entirely conducted by CORESTA (Cooperation Centre for Scientific Research Relative to Tobacco), an international organisation whose membership is "dominated by the tobacco industry, including both state monopolies and multinational companies." Bialous and Yach further document the methods by which tobacco companies work through individual national standards bodies to further their interests, such as making proposals via a national member body. ${ }^{10}$

Public health groups fall by the wayside-While consumer and health organisations often have difficulty competing with the industry's tactics, they do not necessarily lack the resources and technical expertise that would allow them to make a significant contribution to the development of international tobacco standards. Yet, these groups have been, by and large, absent from the process. While a combination of strong resistance from the tobacco industry and passivity on the part of these groups is the likely cause, it should also be noted that ISO's principles for standards development lead the organisation to view businesses as its major stakeholders. As such, consideration for public health, environmental and other social issues are often excluded from the standards development process.

\section{What ought to be done now?}

It is evident that changes need to be made in the way that ISO develops international standards on tobacco. While awareness of public health issues should be raised in general, specific and immediate action could already be taken in the area of tobacco standardization. Several examples of alternative structures, which would permit public health and other non-industry voices to be better heard, are explored.

PLAN 1(A): WIDEN SCOPE FOR ISO'S TOBACCO STANDARDISATION.

The first option is to continue developing international tobacco standards under ISO's technical committee 126 . Keeping the current structure has the advantage of an established mechanism for tobacco standards development, the involvement and support of national standards bodies, and existing policy committees experienced in issues such as developing country matters. Yet, certain improvements such as an amendment to the scope to accommodate greater participation by public health interests at committee meetings are in order. The current scope of the technical committee reads:

Standardization of terminology; methods of test; methods of expression of results (analytical, statistical, etc); specifications concerning as appropriate: tobacco crops and unmanufactured tobacco; manufactured tobacco products; tobacco smoke, including questions of handling, storage, packaging and transport. ${ }^{11}$

As the final report from the Oslo conference noted, there is a need for standards that measure "the biological or epidemiological impact of tobacco products." ${ }^{\circ}$ Thus, the first step to improving ISO's ability to respond to health and safety needs is to initiate an amendment to the scope.

PLAN 1(B): INCREASE PUBLIC HEALTH PARTICIPATION AT ISO'S TECHNICAL COMMITTEE MEETINGS

Equally important, participating national standards bodies should be urged to include public health experts and non-industry scientists in their technical committee 126 member delegation. This second measure comes at an opportune time since ISO declared one of its major strategies for 1999-2001 as: “Increasing ISO's market relevance by . . .more effective representation of consumers and of other social forces." 12 Another way of raising the public health voice at technical meetings is to give liaison status to other consumer and health groups and to promote WHO liaison status from category B to category A. Category B organisations are kept informed of the work of the committee. WHO as a category A liaison, however, would be invited to meetings and be able to make an effective contribution to the work of the technical committee. ${ }^{13}$ Just as tobacco industry tactics involve lobbying individual national standards bodies for their support, the public health community can also work with ISO members and create a market demand for more socially acceptable standards.

PLAN 2: MORE BALANCE BETWEEN ISO AND WHO VIA A MEMORANDUM OF UNDERSTANDING. The second alternative structure involves a more equal collaboration between ISO and WHO. In the past, ISO has signed "memoranda of understanding" with international standardizing bodies, such as the International Telecommunication Union, International Electrotechnical Committee, and United Nations Economic Commission for Europe in the area of electronic business. ${ }^{14}$ Under a memorandum of understanding, the members are expected to "undertake a review of their standardization activities and develop a joint, coordinated programme for standards development and publication which will benefit the market place." ${ }^{14}$ Since a memorandum of understanding is open to international, 
regional, governmental, and consumer organisations whose core mission involves standards setting, an opportunity exists for WHO to sign a memorandum of understanding with ISO on tobacco and tobacco products. The advantage of this option is the potential for achieving a balance between WHO's focus and expertise on public health and ISO's emphasis on facilitating trade, industry participation, and support from national standards bodies.

OTHER: FCTC TREATY AND SACTPR COMMITTEE TO RAISE PUBLIC HEALTH ISSUES IN STANDARDS DEVELOPMENT

As negotiations for the FCTC forge ahead, the possibility for a related protocol on tobacco product regulation is being explored. This protocol would "adopt standards for the regulation of the contents of tobacco products, including standards for testing and measurement, design, manufacturing and processing ..." (WHO 2000, unpublished document $\mathrm{A} / \mathrm{FCTC} / \mathrm{WG} 2 / 3)$. If the framework convention along with the product regulatory component becomes a binding agreement within the next few years, this international treaty may be used to highlight public health issues related to tobacco standardisation at ISO. Another development that may serve to strengthen cooperation between public health advocates and standards developers is the recently convened scientific advisory committee on tobacco product regulation (SACTPR). As an international expert group created under WHO authority, its mission is to "guide international policy development with respect to product regulation and facilitate access to scientific information needed for tobacco regulation" (WHO 2000, unpublished document A/FCTC/WG2/2 Add. 1). The SACTPR could also undertake a review of existing tobacco standards and provide technical expertise in future standards development. While increased collaboration between ISO and WHO would improve public health acceptability of tobacco standards, another alternative is to request an independent group, such as the Consumer Union, to be responsible for the testing of tobacco products. This option should be explored if collaboration between WHO and ISO comes to a standstill.

\section{Conclusion}

Concerned with ISO's existing standards on tobacco, many countries are beginning to develop their own set of standards. Yet, the need to develop and harmonise a new generation of tobacco standards and to combat industry arguments in the process remains unchanged. These suggested alternatives, each with a varying degree of involvement from industry and public health advocates, present an opportunity to rectify the unacceptable way in which tobacco standards are being developed now. In the meantime, the public health community must be proactive, more than ever before, in challenging the existing tobacco standards development process.

ANNE HAN

\section{A_Han@bigfoot.com}

Special thanks to the World Health Organization for the opportunity to conduct research on this paper during a summer internship.

1 International Organization for Standardization. What is ISO? Geneva: ISO, 1999.

2 ISO. Why is international standardization needed? Geneva, Switzerland: ISO, 1999.

3 International Organization for Standardization/Technical Committee 126. ISO 4874: Sampling of batches of raw material. Geneva: ISO, 1981.

4 ISO/TC 126. ISO 3308: Routine analytical cigarette-smoking machine - definitions and standard conditions. Geneva: ISO, 2000.

5 Bates C, McNeill A, Jarvis M, et al. The future of tobacco product regulation and labelling in Europe: implications for the forthcoming European Union directive. Tobacco Control 1999;8:225-35.

6 World Health Organization. Tobacco Free Initiative. Final report: advancing knowledge on regulating tobacco products. Oslo, Norway: WHO; 2000.

7 International Organization for Standardization. How are ISO standards developed. Geneva: ISO, 1999.

8 Lusby L. Halfway down the stairs-possible roles for regional standards bodies. ISO Bulletin 2000;31:2.

$9 \mathrm{ISO} / \mathrm{TC}$ 126. Meeting information in Bristol on October 19-21，1999. http://isotc.iso.ch/livelink/ 1lview/Meeting information?func $=$ doc. View\&nodeId $=91956 \&$ docTitle $=$ Meeting+information, accessed on 29 May 2000.

10 Bialous S, Yach D. Whose standard is it, anyway? How the tobacco industry determines the International Organization for Standardization (ISO) standards for tobacco and tobacco products. Tobacco Control 2001;10:96-104.

11 ISO/TC 126. TC 126 Tobacco and tobacco products. Geneva: ISO, 1999

12 ISO. ISO in the new century. Strategies for 1999-2001. Geneva, ISO, 1998.

13 International Organization for Standardization. Liaison with other organizations. In: ISO/IEC directives part 1 Geneva: ISO, 1997:15.

14 ISO. "ITU joins MoU on electronic business in support of e-commerce.” ISO Bulletin May 2000;31:17. 